\title{
$\mathfrak{S} \mathfrak{t} \mathfrak{a} \mathfrak{t} \mathfrak{l} \mathfrak{t}$
}

bes

\section{Dentiden Furiftentages.}

$\S 1$.

Der 3 wed beả beutidjen Juriftentages̉ iît: eine Bereinigung für ben

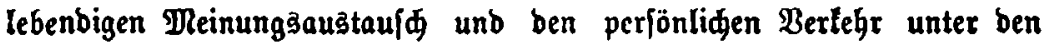
beutjकen Suriften zu bilben; auf ben Bebieten bea gejamten bürgerlidien

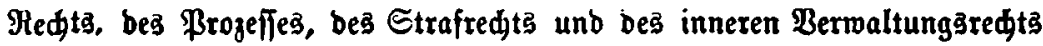
ben Forberungen nad einbeitlider Entwiđelung immer größjere Inerfennung zu ver[daffen, bie Şinbernifje, welde biejer Entmidelung entgegenfleben, zu bejeidnen unb fid über Sorjdläge zu verftänbigen, welde geeignet fino, bie Red̆tseingeit zu förbern.

$\S 2$.

Dex beutjळe Suriftentag tritt in ber Regel alljähtlid jufammen,

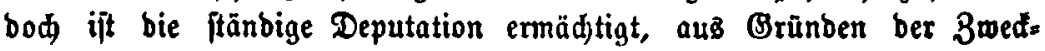

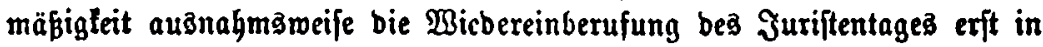
bem auf beffen lek̨ten 3ujammentritt folgenben zweiten Ralenberjahre vorzunęgmen.

\section{$\S 3$.}

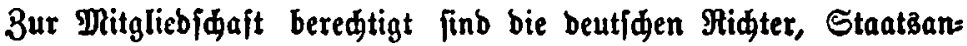

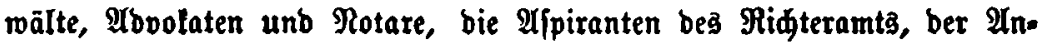
waltfdaft unb bes Rotariats, fowie jeber, ber nađ feinen \&anbes̄gefę̧en

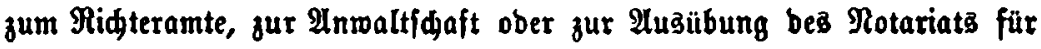
befähigt erfannt ift, ferner bie Rehrer an ben beutjhen 5odjidulen, bie Mitglieber ber gelehrten Altabemien, bie Doftoren ber Recte unb bie redtşgelehrten MRitglieber ber Werwaltungăbebörben.

*) Iuf bem 30. Juriftentag if folgenbe authentifde Auslegung ber iblolien roorben:

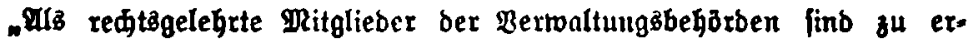

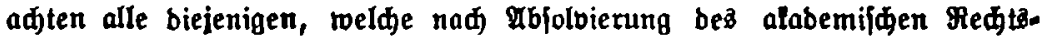
fubiums eine juriftifje Etaatapräfung befanben baben." 
$\S 4$.

Die Ditgliebiळaft beginnt mit bem Cmpjange ber Mitgliebslarte. Sie beredigt gur Xeilnabme an ben Betbanblungen unb an ber $\mathfrak{A b}$ fimmung.

\section{\$5.}

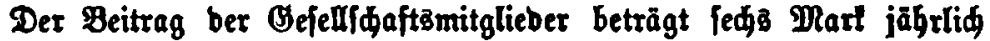

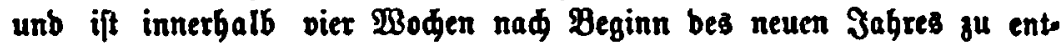
ridten, wibrigenfalls berfelbe burd \$oltoorfdußs eingezogen wirb. Nimmt ein Pitglieb ben mit Poftrorfduß bej内werten Prief nidt an, fo wirb

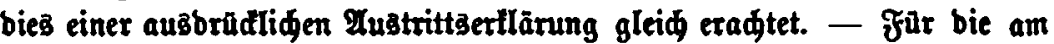

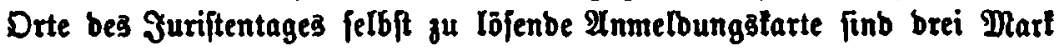
zu entridter.

\section{\& 6.}

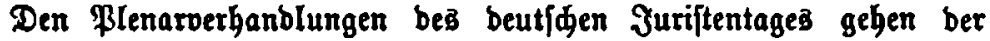

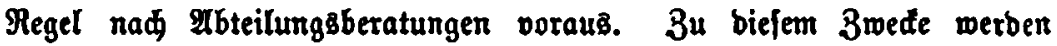
naథ Pebürfniş vier थbteilungen gebilbet, nämlid:

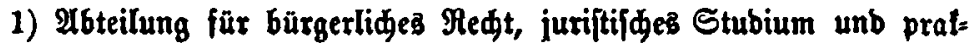
tiifbe $\mathfrak{A}$ uảbilloung.

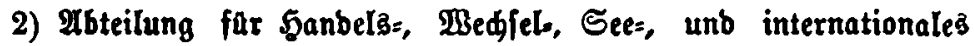
अtedt.

3) Abteilung für Strafredt, Strafprozę unb Befängnisెmejen.

4) शbteilung für Breridts̄verfaffung unb Bivilprozeßs.

Riegen Beratungägegenftänbe aus bem Bebiete bes Berwaltungä: redtes oor, fo merben fie in ber Regel einer biefer 2 tbteilungen zus gerwiejen.

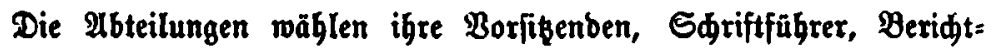
erftatter unb benadridtigen ben Borizenben ber Blenarverjammlung $(§ 7)$, fobalb ibre Beratungen über einzelne Begenftänbe geldIoffen finb; igre Inträge finb fíriftlid ou faffen.

Sämtlide Bejळlaffe ber Obteilungen werben in ber \$lenarverjamm: lung mitgeteilt. Es finbet jebod cine Erörterung unb Ent [deibung im Blenum nur bann ftatt, wenn biejelbe von ber betreffenben $\mathcal{A b t e i l u n g}$ vorgefdlagen, ober menn fie von minbeftens zehn Mitgliebern beantragt unb von ber \$lenarverfammlung vorgejdlagen wirb. Über bie Bors frage, ob bem von minbeftens zebn Mitgliebern geftellten Intrage auf Blenarent|deibung ftattzugeben, wirb nur eirem ber Antragfteller unb bem Peridgterftatter bas $\mathfrak{M}$ ort exteilt. 
§7.

Die Berbanblungen ber Plenarberfammlung leitet ein Borfikenber, welder für bie Dauer eines jeben Juritentages in ber exiten Plenarber: fammlung burd Stimmzettel ober Afflamation gewäblt wirb. Derfelbe benennt zmei bis vier Stellvertreter und vier Sdriftfügrex. Er beftimmt bie Tagesorbnung unb tann eingelne Begenftänbe, obne Borberatung in ben $\mathfrak{A b t e i l u n g e n ~ ( \$ ~ 6 ) , ~ u n m i t t e l b a r ~ j u r ~ \$ l e n a r b e r a t u n g ~ f t e l l e n . ~ T u d ~ i f t ~}$ er befugt, Nidtmitglieber ala Zubörer zuzulaffen.

$\S 8$.

Bei allen Bejdlaffen ber Plenarberjammlung unb ber 9fbteilungen entfdeibet einfade Mlajorität ber anmejenben MRitglieber, bei allen $23 a b l e n$ relative Mlajorităt unb im Fralle ber Stimmengleigheit bas 203 .

$\S 9$.

Mirb $\varsigma_{\text {djluß }}$ ber Debatte beantragt, fo wirb über biefen Antrag fofort abgejtimmt. I্n ber Plenarverfammlung find alle Inträge mit

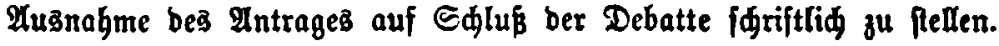

$\S 10$.

Bor bem Saluffe eineả jeben Juriftentages wirb von ber \$lena verfammlung burd Ifftlamation ober in einem eingigen Slrutinium burd Etimmzettel eine aus neunzehn Mitgliebern unb bem \$räjibenten bez

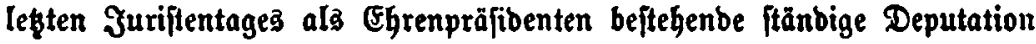
gemählt. Die Siffte ber zur Altlamation vorzuldlagenben Berionen wirb burdy ben Präfibenten ber Plenarverfammlung, feine Stellvertreter unb je zebn von jeber 9tbteilung gewählte Bettrauensmänner gemein|daftlid feftgefitellt.

Die ftänbige Deputation hat folgenbe Befugniffe unb Obliegenheiten:

1) Fie forgt für bie 2 dubführung ber von bem Suriftentage gefaßsten

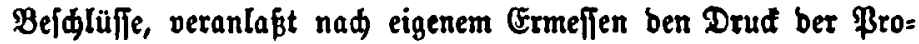
tololle und Borlagen, bemirlt bie Betteilung ber Drudfaden an bie Mitglieber unb verwahrt alle Itten unb Sdriftitude beä Suriftentages;;

2) Fie bejtimmt Beit unb Drt beß̧ näळften Suriftentages, trifft bie für Denfelben nötigen Borbereitungen, erläpt bie Cinlabungen, ftellt bie vorläufige Tagez̧orbnung auf, wobei fie in ber Megel nur bie bis gum 31. Dai bes laufenben Jahres eingegangenen 


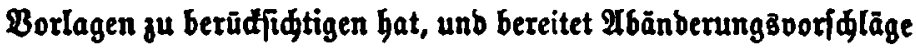

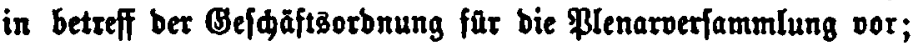

3) Fie nimmt bie BeitrittBettlärungen neuer Ditglieber entgegen, fertigt bie Mitgliebşlarten aus,, empfängt bie Beiträge, beftreitet bie Yuaggaben unb Iegt ber folgenben Deputation Rednung;

4) Fie ergängt fíd felbft, falls eins ober mehrere Mitglieber wäbrenb

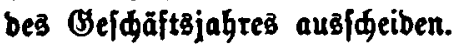

Die Deputation wäblt aus igrer Mitte einen Borfizenben, einen Sdrriftfabrer, welder ein von ber Deputation feftzulekendes \$aujd:

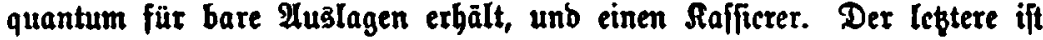
verpflidtet, ber flänbigen Deputation bei igrem jebes̈maligen 3ufammen= tritt einen Maf̂enabidluß vorgulegen. Die Deputation läßt burd eines

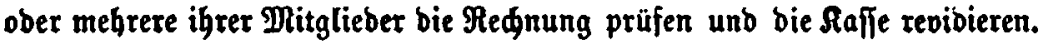

Die Deputation beftimmt Drt unb Beit ifrer Bufammenfunft. Bur Bültigfeit i̧̧rer Befdläfle ift bie Cinlabung fämtlider Mitglicber, forwie bie Mitmirfung von menigftens fünf $\mathfrak{D i t g l i e b e r n ~ e r f o r b e r l i d . ~}$

\section{§ 11.}

Abänberungen biefeă Statuts tōnnen zwar von ber ßlenarverjamm: Iung burd einfade Stimmenmebrheit, jebod nur auf fabriftliden $\mathfrak{A n t r a g}$, ber vier $\mathfrak{B B}_{0}$ en vor bem $\mathbf{3}$ ufammentritt beş Juriftentageș ber ftänbigen Deputation (\$10) äberreidt worben, befdloffen werben. 